\title{
Correlation and Path Coefficients among Quantitative Traits in Wheat (Triticum aestivum L.)
}

\author{
Bal Krishna Joshi ${ }^{1}$ Ashok Mudwari ${ }^{2}$ and Dhruba Bahadur Thapa ${ }^{2}$ \\ ${ }^{1}$ Biotechnology Unit, Nepal Agricultural Research Council (NARC), Khumaltar \\ ${ }^{2}$ Agriculture Botany Division, NARC, Khumaltar, Lalitpur \\ e-mail: joshibalak@rediffmail.com
}

\begin{abstract}
Since many of the quantitative plant characters of economic values are highly influenced by environmental condition, the progress in breeding in such a population is primarily conditioned by the magnitude, nature and inter-relations of genotypic and non-genotypic variations in plant characters. Therefore we estimated phenotypic, genotypic and environmental correlation coefficients and path coefficients among eight quantitative traits of bread wheat to make selection efforts more efficient. These traits were measured in 30 wheat genotypes, which were laid out in a randomized block design with three replications in Khumaltar, Kathmandu during 2003. The highest genotypic correlation (0.81) was between heading and maturity days. Tiller number was negatively correlated with grain number per spike (-0.78) at genetic level. Phenotypically, number of grains and grain weight per spike showed the largest coefficient (0.92) and maturity days exhibited negative association with plant height (-0.37). Environmental correlation coefficient was the highest between tillers number and grain yield (0.5) and heading days showed negative relationship with grain yield $(-0.28)$. It indicates that number of tiller and grains per spike are the most important traits for yield. In most of the cases, genotypic correlations were higher than phenotypic correlations. Maturity days exerted the greatest influence (2.41) directly upon yield. Negative direct effect of heading days and positive effect of tiller number on yield was also considerable on magnitude. Indirect effect of heading days via maturity days was the highest followed by spike grain weight via maturity on grain yield. Results showed that grain filling period is an important factor and number of tillers and grains per spike should also be considered during selection for getting high yielding genotypes.
\end{abstract}

Key words: correlation coefficients, path coefficients, quantitative traits, wheat genotypes

\section{Introduction}

Conventional breeding has dominated the wheat improvement program in Nepal. Due to the availability of diverse wheat genotypes, wild relatives (Mudwari 1999, Upadhyay \& Joshi 2003, Joshi et al. 2004, Mudwari et al. 2005) and introduced genotypes (NARC 1997), breeding efforts are well recognized among the farmers for meeting their diverse needs. Modern cultivars have covered $90 \%$ of the wheat area (Bhatta et al. 2000). Selection has prime importance in crop improvement program therefore selection aids could play a significant role in achieving breeding goals.

Correlation and path coefficient analyses would assist in the choice of characters whose selection would result in the improvement of a complex character such as yield. Correlation estimates the degree of association between variables. Path analysis is useful to know the indication of which variables exert an influence on other variables while recognizing the multicolinearity
(Akanda \& Mundit 1996). Path coefficient analysis has been useful in determining selection criteria in a number of crops such as wheat (Fonseca \& Patterson 1968, Mudwari 1985, Akanda \& Mundit 1996), maize (Ivanovic \& Rosic 1985), soybeans (Pandey \& Torrie 1973), rice (Rao et al. 1997, Joshi 2003).

In the breeding history of wheat in Nepal, estimates of these coefficients were not common. Therefore this investigation was undertaken for developing the selection criteria based on magnitude and direction of correlation and direct and indirect effects among metric traits.

\section{Materials and Methods}

A total of 28 advanced wheat lines and two-released wheat cultivars were evaluated in an initial evaluation trial at Agriculture Botany Division, Khumaltar, Kathmandu during 2003. Standard agronomical 
practices were followed. Eight traits namely heading days, maturity days, plant height, tiller number, grain number, spike grains weight, 1000-grain weight and grain yield were measured from these 30 wheat genotypes which were laid out in randomized complete block design with three replications.

Based on these replicated data, phenotypic, genotypic and environmental correlation coefficients were estimated among the quantitative traits. Path analysis was based on genotypic correlation coefficients and estimated following the procedure of Dewey and Lu (1959). Data were processed in MS Excel and analyzed in MINITAB and AGROBASE softwares.

\section{Results and Discussion}

Correlation coefficients (r) of all possible pairs of eight traits were estimated in terms of phenotypic, genotypic and environmental characters (Table 1). Heading days were highly correlated with maturity days at phenotypic level. These were negatively associated with plant height, tiller number and grain yield. Relationship between maturity days and spike grain weight was strong in positive direction. Negatively related traits with maturity were plant height, tiller number and 1000-grain weight. Plant height showed negative coefficient values with tiller number, spike grains number and grain yield. Strongly correlated trait was tiller number and grain yield. Tiller number was negatively related with spike grain number and 1000-grain weight. The highest rvalue was between spike grains number and spike grains weight. However, spike grains number and 1000-grain weight were negatively associated. Relatively, r-values of spike grains weight were higher with 1000-grain weight and grain yield. Phenotypically, three traits, namely tiller number, spike grains number and spike grains weight can be considered during selection to increase yield.

Table 1. Phenotypic (Pr), genotypic (Gr) and environmental correlation coefficients (Er) among metric traits estimated from 30 wheat genotypes

\begin{tabular}{|c|c|c|c|c|c|c|c|c|c|c|}
\hline$\overline{\mathrm{SN}}$ & & & 1 & 2 & 3 & 4 & 5 & 6 & 7 & 8 \\
\hline & & $\operatorname{Pr}$ & & 0.7857 & -0.2386 & -0.0995 & 0.0332 & 0.1209 & 0.0345 & -0.0493 \\
\hline \multirow[t]{3}{*}{1} & Heading days & $\mathrm{Gr}$ & & 0.8122 & -0.2612 & -0.0979 & 0.0216 & 0.0274 & 0.0316 & 0.0024 \\
\hline & & Er & & 0.4750 & -0.0333 & -0.2048 & 0.1114 & 0.4950 & 0.0739 & -0.2488 \\
\hline & & $\operatorname{Pr}$ & & & -0.3724 & -0.2043 & 0.2157 & 0.0891 & -0.0227 & 0.0746 \\
\hline \multirow[t]{3}{*}{2} & Maturity days & $\mathrm{Gr}$ & & & -0.4538 & -0.2620 & 0.5864 & 0.2738 & 0.0234 & 0.1908 \\
\hline & & $\mathrm{Er}$ & & & 0.2656 & -0.1823 & -0.0405 & -0.0507 & -0.1825 & -0.0971 \\
\hline & & $\operatorname{Pr}$ & & & & -0.0237 & -0.0180 & 0.0362 & 0.0369 & -0.0112 \\
\hline \multirow[t]{3}{*}{3} & Plant height & $\mathrm{Gr}$ & & & & -0.0881 & -0.1049 & 0.0958 & 0.0739 & -0.0873 \\
\hline & & Er & & & & 0.0233 & 0.0140 & 0.0166 & 0.0047 & 0.0311 \\
\hline & & $\operatorname{Pr}$ & & & & & -0.0689 & 0.1377 & -0.0165 & 0.5499 \\
\hline \multirow[t]{3}{*}{4} & Tillers number & $\mathrm{Gr}$ & & & & & -0.7481 & -0.5244 & -0.2314 & 0.6612 \\
\hline & & Er & & & & & 0.1852 & 0.3905 & 0.1721 & 0.4951 \\
\hline & & $\operatorname{Pr}$ & & & & & & 0.9211 & -0.1766 & 0.1059 \\
\hline \multirow[t]{3}{*}{5} & Spike grain number & $\mathrm{Gr}$ & & & & & & -0.2458 & -0.4416 & 0.0582 \\
\hline & & $\mathrm{Er}$ & & & & & & $1.00 ?$ & -0.0753 & 0.1215 \\
\hline & & $\operatorname{Pr}$ & & & & & & & 0.3701 & 0.3706 \\
\hline \multirow[t]{3}{*}{6} & Spike grain weight & $\mathrm{Gr}$ & & & & & & & 0.6939 & 0.5250 \\
\hline & & $\mathrm{Er}$ & & & & & & & 0.2705 & 0.3342 \\
\hline & & $\operatorname{Pr}$ & & & & & & & & 0.0901 \\
\hline \multirow[t]{2}{*}{7} & 1000 -grain weight & $\mathrm{Gr}$ & & & & & & & & 0.3793 \\
\hline & & Er & & & & & & & & -0.1000 \\
\hline 8 & Grain yield & & & & & & & & & \\
\hline
\end{tabular}


In most of the cases, genotypic r-values were higher than phenotypic and environmental characters. Similar result was also reported by Mudwari (1985). Heading days were highly correlated with maturity days at genotypic level. It was negatively associated with tillers number and plant height. Similar trend of maturity days was with plant height and tillers number. It indicates that maturity days could be useful to increase spike grains number and spike grains weight. Negatively related traits with plant height were tillers number, spike grains number and grain yield. Tillers number showed strong association with grain yield but it was negative with spike grains number, spike grains weight and 1000grain weight. Correlation value between spike grains number and grain yield was not considerable in magnitude. Spike grains number was negatively correlated with spike grains weight and 1000-grain weight. The r-values of spike grains weight with 1000grain weight and yield, and of 1000-grain weight with grain yield were high in positive direction. Genotypic correlation study showed the importance of tillers number, spike grains weight, 1000-grain weight to consider them during selection.

Environment favoring the tillering capacity and spike grains weight was helpful for increasing grain yield. Environmental correlation coefficient between 1000-grain weight and grain yield was negative. Positive relationships between heading days and maturity days, heading days and spike grains weight, tillers number and spike grains weight, spike grains number and spike grains weight were high.

The direction and magnitude of r-values are very useful during selection of genotypes. In wheat, tillers number, spike grains number and 1000-grain weight are major yield components. In this study four traits namely tillers number, spike grains number, spike grains weight and 1000-grain weight were very important for grain yield improvement. Grain filling period was also equally important.

Significant positive genotypic correlations of grain yield with tillers number, spike grains number, 1000grain weight and plant height were reported by Mudwari (1985). He also observed significant negative genotypic correlations of grain yield with days to heading and days to maturity. In the study of Moghaddam et al. (1998), plant height was positively correlated with number of tillers and straw biomass per plant but negatively associated with number of grains per spike, grains yield and harvest index.

The negative relationship between vegetative period and grain filling period under drought stress condition was reported by Simane et al. (1993). Akanda and Mundit (1996) reported that in some cases yield component compensation was indicated by the presence of negative correlations among the yield components.

Partitioning the genotypic correlation coefficients into direct and indirect effects could help further for understanding the relative importance of traits with each other. The direct positive effects of maturity days and tillers number on yield were higher (Table 2). The effects of plant height and 1000-grain weight on yield were also high and positive. Spike grains number, spike grains weight and heading days exerted negative direct influence on yield.

Table 2. Direct (diagonal) and indirect path coefficients of metric traits on yield of wheat

\begin{tabular}{lllllllll}
\hline SN & Character & 1 & 2 & 3 & 4 & 5 & 6 & 7 \\
\hline 1 & Heading days & $\mathbf{- 1 . 7 3 5 1}$ & 1.9587 & -0.1425 & -0.0734 & -0.0126 & -0.0035 & 0.0108 \\
2 & Maturity days & -1.4093 & $\mathbf{2 . 4 1 1 5}$ & -0.2477 & -0.1963 & -0.3404 & -0.0350 & 0.0080 \\
3 & Plant height & 0.4531 & -1.0942 & $\mathbf{0 . 5 4 5 8}$ & -0.0660 & 0.0609 & -0.0122 & 0.0254 \\
4 & Tiller number & 0.1699 & -0.6319 & -0.0481 & $\mathbf{0 . 7 4 9 2}$ & 0.4343 & 0.0671 & -0.0794 \\
5 & Spike grain number & -0.0375 & 1.4140 & -0.0572 & -0.5604 & $\mathbf{- 0 . 5 8 0 6}$ & 0.0314 & -0.1515 \\
6 & Spike grain weight & -0.0476 & 0.6603 & 0.0523 & -0.3929 & 0.1427 & $\mathbf{- 0 . 1 2 7 9}$ & -0.0182 \\
7 & 1000-grain weight & -0.0548 & 0.0564 & 0.0403 & -0.1733 & 0.2564 & -0.0887 & $\mathbf{0 . 3 4 3 1}$ \\
\hline
\end{tabular}

Residual factors: 0.259 
The residual effect determines how best the studied traits account for the variability of the yield. These seven traits explained about $75 \%$ of the variability in the grain yield.

Indirect effects of these seven traits on grain yield are given in Table 2. Heading days exerted positive indirect effect on yield via maturity days but negative indirect effect on yield via plan height. Maturity days showed negative indirect effects on yield via all the traits except 1000-grain weight. The magnitude of indirect effect of plant height via heading days and maturity days were considerable which were at positive and negative directions respectively. Similarly, negative value of tillers number via maturity days and positive value via spike grains number indicates their relative contribution towards yield. The indirect high effects of spike grains number via maturity days and tillers number were positive and negative respectively. Indirect positive effect of 1000-grain weight via spike grains number and negative effect via tillers number were also important.

Mudwari (1985) found that the number of spikelets per spike exerted the greatest influence directly and indirectly upon grain yield. The direct effect of days to heading on grain yield was negligible, whereas that of plant height, spike grain number and grain weight was moderate to high. The negative correlation between plant height and grain yield was due to indirect negative effects mainly via grain number, maturity days and grain weight. Similar results were reported by Moghaddam et al. (1998). Significantly positive direct effect of tillers number on grain yield was also reported by Siamane $e t$ al. (1993). In his study, grain per spike had the largest direct effect. Akanda and Mundit (1996) reported that the components with the highest correlations to yield also had the largest direct effects on yield. Of the studied traits, tillers number exerted the largest direct influence on yield. Similar type of finding was reported by Akanda and Mundit (1993). Our results indicate that, tendem selection is effective for tiller number and 1000-grain weight, simultaneous selection for spike grain number and restricted selection for plant height.

Traits developed at extreme stage of growth e.g. tiller number and 1000-grain weight show relatively higher coefficients. Correlation study suggests that tillers number was the most important trait for selecting high yield, spike grains weight the second and 1000grain weight the third important selection criteria. Path coefficient study revealed that tiller number, plant height and 1000-grain weight were the first, second and third most important traits respectively that can be considered during selection process. Maturity days have also high direct effect but its indirect effects with other traits suppress the importance of this direct effect. We hope that these findings will be useful to all dedicated wheat breeders.

\section{Acknowledgment}

This work was financially supported by Nepal Agricultural Research Council, Kathmandu.

\section{References}

Akanda, S.I. and C.C. Mundit. 1996. Path coefficient analysis of the effects of stripe rust and cultivar mixtures on yield and yield components of winter wheat. Theor. Appl. Genet. 92: 666-672.

Bhatta, M.R., G.O. Ferrera, B. Gurung, T.P. Pokharel, N.R. Gautum, P. Gurung and R.B. Neupane. 2000. Present status of participatory plant breeding research on wheat at the National Wheat Research Programme, Nepal. In: An exchange and experiences from South and South East Asia. Proceedings of the Intl. Symp. on PPB and PPGR enhancement, (1-5 May 2000), Pokhara, Nepal. PRGA, IDRC, DFID, DDS, LIBIRD, IPGRI and ICARDA. pp. 391-398.

Dewey, D.R. and K.H. Lu. 1959. A correlation and path analysis of components of crested wheat grass seed production. Agron. J. 51: 515-518.

Fonseca, S. and F.L. Patterson. 1968. Yield component heritabilities and interrelationships in winter wheat (Triticum aestivum L.). Crop Sci. 8:614-617.

Ivanovic, M. and K. Rosic. 1985. Path coefficient analysis for three stalk traits and grain yield in maize (Zea mays L.). Maydica 30:233-239.

Joshi, B.K., A. Mudwari, M.R. Bhatta and G.O. Ferrara. 2004. Genetic diversity in Nepalese wheat cultivars based on agromorphological traits and coefficients of parentage. Nepal Agric. Res. J. 5:7-18.

Joshi, B.K. 2003. Correlation and path coefficient analyses of yield and yield components in $\mathrm{F}_{1}$ hybrids rice and their parents. Bangladesh J. Agric. Res. 28(4): 533-540.

Moghaddam, M., B. Endaie and J.G. Waines. 1998. Genetic variation for and interrelationships among agronomic traits in landraces of bread wheat from southwestern Iran. J. Genet. Breed. 52:73-81

Mudwari, A., D.B. Thapa, M.R. Bhatta, T.P. Pokhrel, R.P. Sah, D.R. Bhandari, B. Sharma, L. Ghale, A.R. Lohani, B. Bhandari, S. Pariyar, G.O. Ferrara and B.K. Joshi. 2005. Participatory varietal selection in wheat for identifying farmers preferred variety and disseminating technology faster. In: Agricultural technologies for poverty reduction. Proc. of $7^{\text {th }}$ National Outreach 
B. K. Joshi et al./Correlation and Path Coefficients among

Research Workshop, 24-25 June 2004 (Eds. Y.N. Ghimire \& K.R. Bhatta). Nepal Agricultural Research Council, Kathmandu. pp.171-184.

Mudwari, A. 1999. Wild relatives of wheat and its status in Nepal. In: Wild relatives of cultivated plants in Nepal. Proceedings of national conference (2-4 June 1999) Kathmandu (Eds. R. Shrestha \& B. Shrestha). GEMNepal. pp.83-89.

Mudwari, A. 1985. Studies on genetic variability, path analysis and selection indices on some biometric characters in rainfed wheat (Triticum aestivum L.). M.Sc. thesis. Rajasthan College of Agriculture, Udaipur, India.

NARC. 1997. Twenty five years of wheat research in Nepal (1992-1997). NARC, NWRP, Nepal.
Pandey, J.P. and J.H. Torrie. 1973. Path coefficient analysis of seed yield components in soybeans (Glycine max $\mathrm{L}$. Merr.). Crop Sci. 13: 505-507.

Rao, S.A., M.A. Khan, T. McNeilly and A.A. Khan. 1997. Cause and effect relations of yield and yield components in rice (Oryza sativa L.). J. Genet. Breed. 51: $1-5$.

Simane, B., P.C. Struik, M.M. Nachit and J.M. Peacock. 1993. Ontogenetic analysis of yield components and yield stability of durum wheat in water-limited environments. Euphytica 71:211-219.

Upadhaya, M.P. and B.K. Joshi. 2003. Plant genetic resources in SAARC countries: Their conservation and management. Nepal chapter. SAARC Agriculture Information Center. pp. 297-422. 
Nepal Journal of Science and Technology 9 (2008) 